\title{
Association of the APOE- $\varepsilon 4$ allele in Mexican older adults with cognitive impairment
}

\author{
Israel de Jesús García-Muñoz \\ Secretaría de Salud, Instituto Nacional de Rehabilitación "Luis Guillermo Ibarra Ibarra", Department of Geriatrics, Ciudad de México, Mexico
}

The article "Program for APOE- $\varepsilon 4$ allele detection in a Mexican population of older patients with cognitive impairment", published in Gaceta Médica de México number 5 of $2018^{1}$ is presented as the "first study implemented in Mexico to know the risk of that allele for neurocognitive disorders". In this regard, it is important to make some observations:

- It is not the first study in the Mexican population analyzing the presence of the APOE- $\varepsilon 4$ allele in cognitive impairment. In 2008, Villalpando Berumen et al. $^{2}$ published an investigation that evaluated this association; they did not find differences in the frequency of presentation of the APOE $\varepsilon 3$ and $\varepsilon 4$ alleles in subjects with and without criteria consistent with Alzheimer-type dementia adjusted for age, gender and level of education, unlike the results reported by Genis Mendoza et al.
- The APOE- $\varepsilon 4$ allele has been established as a risk factor for familial and sporadic Alzheimer-type dementia, but no significant association has been found for other types of dementia or neurocognitive disorders. Considering the above, in the article we comment here, the study population with major neurocognitive disorder is not categorized or stratified with probability diagnoses for the different types of dementia, which would have established a more solid and reliable association.

\section{References}

1. Genis-Mendoza AD, Martínez-Magaña JJ, Bojórquez C, Téllez-MartínezJA, Jiménez-Genchi J, Roche $A$, et al. Programa de detección del alelo APOE- $\varepsilon 4$ en adultos mayores mexicanos con deterioro cognitivo. Gac Med Mex. 2018;154:555-560.

2. Villalpando-Berumen JM, Mejía-Arango S, Aguilar-Salinas CA, OrdónezSánchez ML, Gutiérrez-Robledo LM. Apolipoprotein E epsilon4, Alzheimer's disease, and cognitive performance in elderly Mexican mestizos. J Am Geriatr Soc. 2008;56:677-682.
Gac Med Mex. 2019;155:104-104

Contents available at PubMed www.gacetamedicademexico.com 